\title{
The Influence of the Wet Processing Stages on Yarn Processability
}

\section{El-Hadidy AM, El-Rys SM* and El-Hossiny A}

Textile Engineering Department, Mansoura University, Egypt

\begin{abstract}
In this study, the influence of the wet processing stages, on cotton yarn processability was investigated. The yarn samples were collected after every treatment and tested for knitability efficiency. The total evaluation of the yarn properties was measured by using performance diagram. It was found that the highest processability index was occurred after mercerization conditions of $26^{\circ} \mathrm{Be}$ at temperature $19^{\circ} \mathrm{C}$, vat dyeing and at temperature $19^{\circ} \mathrm{C}$, reactive dyeing. While maximum processability index with reactive dyeing was occurred with mercerization condition of $28^{\circ} \mathrm{Be}{ }^{\prime}$ at temperature $24^{\circ} \mathrm{C}$.
\end{abstract}

Keywords: Knitability; Wet processing stages; Processability index; Processability chart and performance diagram

\section{Introduction}

Single jersey knitted fabrics is generally used to make outerwear garments such as T-shirts. The knitted yarns undergo a series of different processing treatments like scouring, bleaching, dyeing, softener padding and relax drying. These processes are carried out to impart a particular property related to that process like scouring for absorbency, bleaching for whiteness, dyeing to impart color to fabric and finishing for improving softness and handle of the fabric.

Finally, there is the fact that, done right, cotton is really an excellent choice for summer weaving specially to summer knitting (ladies 100\% cotton T-shirt).

A T-shirt is something to look forward to at the end of a long day. Slipping in to the soft weave of a jersey knit can take us back in time to childhood, our first rock concert or the summer we fell in love with hot pink.

The properties of knitted fabrics are influenced by various parameters like raw materials, yarn structure, fabric structure, processing stages and finishing. The amount of changes occurred in the properties of the fabric due to these parameters makes the subject complex. Further, the determination of the changes in physical and dyeing properties during different stages of wet processing is important for the control of process parameters to get the final product as the requirements of the customer.

There are limited number of studies on influence of wet processing stages and process sequences on the physical, mechanical properties of knitted yarns has been reported so far.

In this study, the influence of the wet processing stages, on the physical-mechanical-dyeing properties of cotton yarns were investigated.

On the other hand, textile finishing processes are usually used to improve the quality of materials. Among these, mercerization which improves handling and appearance of cotton fibers to simulate the superior properties of synthetic fibers.

The extent of changes that occurs depends on the processing time, caustic concentration, temperature, and degree of polymerization and source of cellulose, and the degree of tension [1].

Bleaching ensures the complete removal of impurities by destroying color matters present in the cotton fibers. The bleaching process can be applied by using hydrogen peroxide or calcium hypochlorite and sodium hypochlorite.

Dyeing is another important wet processing not only to impart colors to materials but also influences on yarn and fabric properties. Cotton and other cellulosic fibers are dyed with direct, sulphur, vat, reactive and more types than for any other fiber. Furthermore, vat dyes are one of the oldest types of dye. Vat dyes in particular give dyeing on cellulosic fibers with the best overall fastness properties [2].

In previous research works, the accessibility was investigated in terms of monolayer capacity, moisture regain, water retention values and diffusion coefficient of the congo red dye after mercerization and other chemical treatments [3].

Mehdi Akhbari [4] investigated the parameters influencing mercerization using RSM method, in order to increase the tensile strength of mercerized yarn. Nazem Samei [5] compared the effects of hot mercerization on open-end and ring spun yarns in slack and under tension conditions. Mercerized yarns were bleached and dyed with reactive dye.

Besides, the influence of different temperature of drying after mercerization and enzymatic scouring through changes in the surface properties and scouring efficiency were investigated [6]. The effect of chemical finishing treatments like scouring, bleaching, mercerization and dyeing on the properties of ring spun and compact yarns were investigated by Subramaniam [7].

\section{Experimental Part}

Before setting a machine with ladies, $100 \%$ cotton T-shirt, it is normal to check if the structure, yarn parameters and machine settings are correct. There are three separate but interconnected tasks described the processability of this structure with this yarn on this machine, in order to obtain the best productivity and quality.

${ }^{*}$ Corresponding author: El-Rys SM, Textile Engineering Department, Mansoura University, Egypt, E-mail: samah_elrys@yahoo.com

Received Septembetr 06, 2015; Accepted Septemeber 21, 2015; Published Septemeber 27, 2015

Citation: El-Hadidy AM, El-Rys SM, El-Hossiny A (2015) The Influence of the Wet Processing Stages on Yarn Processability. J Textile Sci Eng 5: 214 doi:10.4172/2165-8064.1000214

Copyright: (c) 2015 El-Hadidy AM, et al. This is an open-access article distributed under the terms of the Creative Commons Attribution License, which permits unrestricted use, distribution, and reproduction in any medium, provided the original author and source are credited. 
How to check the processability of the input data is still an open field for researchers. There are three main trends: 1) Expert system, 2) physical process simulation, 3 ) an engineering approach. Each of these has its own power and its limitation.

The advantages of expert system are in their ability to collect and operate with a large no. of rules. knitability=ease to knit $=$ knitting performance of the knitted structure for a given yarn [8].

In this part of the investigation the influence of wet processing stages on yarn quality will be investigated.

\section{Experimental design}

Tables 1 and 2 show the relationship between fabric weight per unit area, fabric structure and yarn count respectively.

These values may get up and down. It may be changed.

Plied combed - ring spun cotton yarn with a count of 20/2 Ne was produced. It was spun from Egyptian cotton G86 with (single twist factor $\alpha e=3.6$ and plied twist factor $\alpha e=3.5$ ). Besides, grey yarn without any treatment was produced for comparison.

$$
\text { Yarn Count }(\mathrm{Ne}){ }^{*} \text { Stitch length }{ }^{*} \mathrm{GSM}=\text { "K" }
$$

\section{Methods}

Mercerization: Mercerization was done on jaeggli mercerizing yarn machine. Ten samples of yarn hanks were treated with five caustic soda concentration ranging from $\left(26^{\circ} \mathrm{Be}\right.$ ' to $\left.34^{\circ} \mathrm{Be} e^{\prime}\right)$ with $2^{\circ} \mathrm{Be} e^{\prime}$ intervals, and at two temperatures $\left(19^{\circ} \mathrm{C}\right.$ and $\left.24^{\circ} \mathrm{C}\right)$, using wetting agent [(6-8) $\mathrm{g} / \mathrm{l}$ of floranit -4028 of pulcra chemical]. Both of applied tension and time of treatment were constants. To remove the excess caustic soda after the treatment, the yarn hanks were washed with hot and cold water. The hanks were then neutralized with acetic acid solution $(0.5$ $\mathrm{cm} / \mathrm{l}$ ) to remove any residual alkali. Yarns were finally rinsed with cold water, squeezed with centrifugal forces, dried at $110^{\circ} \mathrm{C}$ for $2 \mathrm{hrs}$.

Bleaching: The same ten samples of the mercerized yarns were bleached in an exhaustion procedure, the bleaching bath containing with $(0.5 \%)$ hydrogen peroxide, $(2 \%)$ of sodium hydroxide, $(2 \%)$ of asbicone (detergent used as assistant factor) and (1\%) of egypttool

\begin{tabular}{|c|c|c|c|c|}
\hline Fabrics GSM & $\begin{array}{c}\text { Plain (Single } \\
\text { Jersey) }\end{array}$ & Rib (1*1) & Pique & Interlock \\
\hline 100 & 36.12 & 47.27 & 47.27 & 59.96 \\
\hline 120 & 33.30 & 39.81 & 44.32 & 55.84 \\
\hline 140 & 30.48 & 37.35 & 40.98 & 51.72 \\
\hline 160 & 27.66 & 34.89 & 37.64 & 47.60 \\
\hline 180 & 24.84 & 32.43 & 34.30 & 43.48 \\
\hline 200 & 22.02 & 29.97 & 30.96 & 39.36 \\
\hline 220 & 19.20 & 27.51 & 27.62 & 35.24 \\
\hline 240 & 16.38 & 25.05 & 24.05 & 31.12 \\
\hline
\end{tabular}

Table 1: Selection of yarn count for various GSM for different fabrics.

\begin{tabular}{|c|c|}
\hline Fabrics & Constant "K" \\
\hline Plain Jersey & 12068.509 \\
\hline Rib 1*1 & 16431.497 \\
\hline Rib 1*2 & 19005.333 \\
\hline Interlock & 24013.800 \\
\hline
\end{tabular}

Table 2: Values of constant "K". (wetting agent). The bleaching was carried out at $100^{\circ} \mathrm{C}$ for $1 \mathrm{hr}$. Acetic acid was used for neutralization.

Dyeing: Half of the quantity of the mercerized and bleached samples of yarns was dyed with vat dyeing and the other half was dyed with reactive dyeing. The final no. of samples was 20 samples (10 samples of vat dyeing +10 samples of reactive dyeing). Dyeing process was carried out by exhaustion procedure on proteks bobbin dyeing machine with liquor ratio 1:6.

Reactive dyeing: (1.5\%) EcoFix.Blue. $\mathrm{R},(5 \mathrm{~g} / \mathrm{l}) \mathrm{Na}_{2} \mathrm{CO}_{3}$ and (20 g/l) $\mathrm{NaCl}$ were adjusted at $50^{\circ} \mathrm{C}$ and then raised to $60^{\circ} \mathrm{C}$ and maintained at this temperature for $90 \mathrm{~min}$ to dye as reactive dyeing. Dyed samples were then washed in a soap solution, then, boiled and softened by using fatty acid, finally, squeezed and dried at $100^{\circ} \mathrm{C}$.

Vat dyeing: Yarns were dyed in a solution containing (1.5\%) Ind.Blue.CLF.(vat dye), (0.1\%) $\mathrm{NaOH}$ and (5 g/l) Sodium hydrosulphite. As known vat dyeing is based on the principle of converting water -insoluble vat dye by alkaline reduction to water-soluble leuco compound having affinity to cotton. Sodium hydro-sulphite is used to the reduction process at $60^{\circ} \mathrm{C}$ then raised to $80^{\circ} \mathrm{C}$ for $20 \mathrm{~min}$, then washed. Finally, it is oxidized by using $\mathrm{H}_{2} \mathrm{O}_{2}$ at $50^{\circ} \mathrm{C}$ for $30 \mathrm{~min}$, then washed and softened by using fatty acid.

\section{Testing methods}

Testing methods were carried on the treated yarns after each treatment and compared to grey yarns. Breaking - load was measured by using USTER @ Tensorapid 4. Color strength and degree of whiteness of yarns were observed by using Data color International SF 600 at D65. Yarn abrasion resistance was measured according to ASTM D6611. In order to measure the coefficient of friction of yarns, friction Coefficient meter F-Meter R-1183. The friction coefficient is determined on the F-meter by using the eytlwein formula as follow:

$\mathrm{T} 2 / \mathrm{T} 1=\mathrm{e}^{\mu \alpha}$

Where:

T1: tension beyond the friction point.

T2: tension before the friction point.

a: friction angle in rad.

$\mu$ : the dynamic coefficient of friction.

\section{Experimental Results and Discussion}

At the end of each treatment process, the yarn samples were collected and tested for some of mechanical and color properties. To compare between the effect of mercerization and the effect of bleaching on the yarns, each of braking-load, coefficient of friction, abrasion resistance, yarn count and color properties were measured. These measured properties are considered as index for ability of yarns to work in the next processes.

\section{Breaking-force}

Figure 1 shows the effect of mercerization and bleaching on the breaking force of mercerized yarns at temperatures $\left(19^{\circ} \mathrm{C}, 24^{\circ} \mathrm{C}\right)$ and at five different $\mathrm{NaOH}$ concentrations. It can be clearly seen that there was an increase in the breaking-load at temperature $24^{\circ} \mathrm{C}$ more than $19^{\circ} \mathrm{C}$ compared to unmercerized (grey) yarn. This increase may be due to the effect of mercerization which causes swelling and transforms the cross section of the fibers from bean-shaped cross section to a circular cross section. 
Citation: El-Hadidy AM, El-Rys SM, El-Hossiny A (2015) The Influence of the Wet Processing Stages on Yarn Processability. J Textile Sci Eng 5: 214. doi:10.4172/2165-8064.1000214

Page 3 of 6

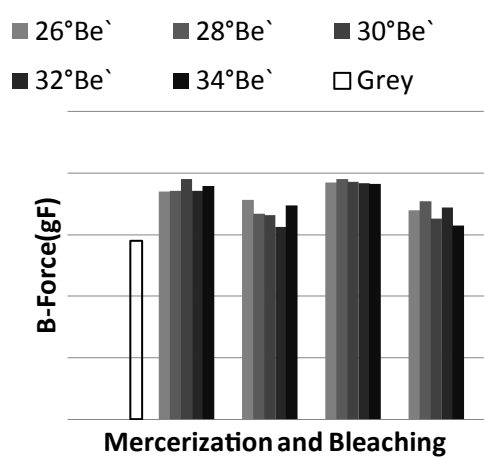

Figure 1: Effect of mercerization and bleaching on b-force at different conditions.
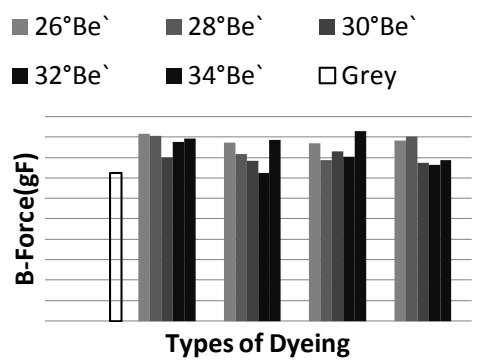

Figure 2: Effect of types of dyeing on b-force at different conditions.

Since the surface area of contact of swollen fibers becomes higher, consequently each of inter fiber friction and cohesion are improved which in turn improves the breaking-Load. In addition, raising the temperature of mercerization treatment lowers the viscosity of caustic soda solution; hence it facilitates the penetration of $\mathrm{NaOH}$ in to the fibers and the swelling of fibers is increased as well. As known, increasing the swelling leads to increasing the degree of mercerization.

After bleaching, there was a slightly decrease in the breaking -load compared to mercerized yarn but still more than the breaking -load of grey yarn for both cases $19^{\circ} \mathrm{C}$ and $24^{\circ} \mathrm{C}$. Breaking-load increased from (1564 to 1786$) \mathrm{gF}$ with average value $(1684) \mathrm{gF}$ at temperature $19^{\circ} \mathrm{C}$, and from (1573 to1774)gF with average value (1679)gF at temperature $24^{\circ} \mathrm{C}$. This decline was occurred because the bleaching using hydrogen peroxide $\left(\mathrm{H}_{2} \mathrm{O}_{2}\right)$ may leads to formation of Oxi- Cellulose which known that it decreases the tensile strength of materials.

Figure 2 shows the effect of two types of dyeing on the breaking -load of this yarn. The results showed that the increasing in the breaking-load after vat dyeing was higher than reactive dyeing in both cases $19^{\circ} \mathrm{C}$ and $24^{\circ} \mathrm{C}$ compared to grey yarn. This increase in vat dyeing is arranged during washing with alkali soap after dyeing process. In addition, the increase of these spaces between fibers with the presence of vat dyeing may be the reason for the rise of the breaking-load. After vat dyeing, the breaking -load raised from (1596 to1828)gF with average value (1753) $\mathrm{gF}$ at temperature $19^{\circ} \mathrm{C}$, and raised from (1575 to1854)gF with average value (1686)gF at temperature $24^{\circ} \mathrm{C}$. On the other hand, after reactive dyeing, the breaking-load raised from (1446 to1767) $\mathrm{gF}$ with average value(1631)gF at temperature $19^{\circ} \mathrm{C}$, and raised from (1529 to1800)gF with average value $(1642) \mathrm{gF}$ at temperature $24^{\circ} \mathrm{C}$.

\section{Yarn count}

Figure 3 shows the effect of mercerization and bleaching on the yarn count of mercerized yarns at temperatures $\left(19^{\circ} \mathrm{C}, 24^{\circ} \mathrm{C}\right)$ and at five different $\mathrm{NaOH}$ concentrations. As shown the yarn count increased after both mercerization and bleaching compared to grey yarn, where, after mercerization it ranged between 60 tex and 64 tex in both cases $19^{\circ} \mathrm{C}$ and $24^{\circ} \mathrm{C}$. This means that the temperature of mercerization didn't affect the yarn count here. However, this increase in yarn count was occurred generally due to the effect of mercerizing process which increases the diameter because of swelling with $\mathrm{NaOH}$ molecules.

Figure 4 shows the effect of two types of dyeing on the yarn count of this yarn. After vat dyeing, the yarn count raised from (57 to 59.5) tex in both cases $19^{\circ} \mathrm{C}$ and $24^{\circ} \mathrm{C}$, whereas after reactive dyeing, it raised from ( 56.5 to 60$)$ tex at temperature $19^{\circ} \mathrm{C}$ and from ( 57 to 62.5$)$ tex at temperature $24^{\circ} \mathrm{C}$.

\section{Abrasion resistance}

Figure 5 shows the effect of mercerization and bleaching on the

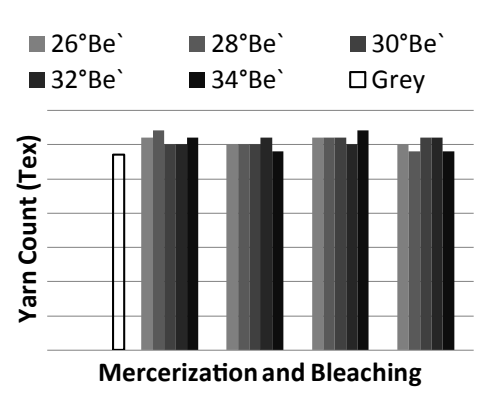

Figure 3: Effect of mercerization and bleaching on yarn count at different conditions.
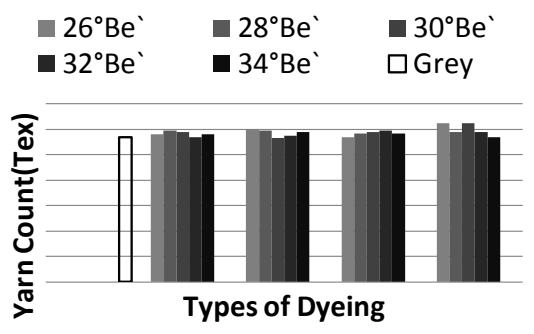

Figure 4: Effect of types of dyeing on yarn count at different conditions.

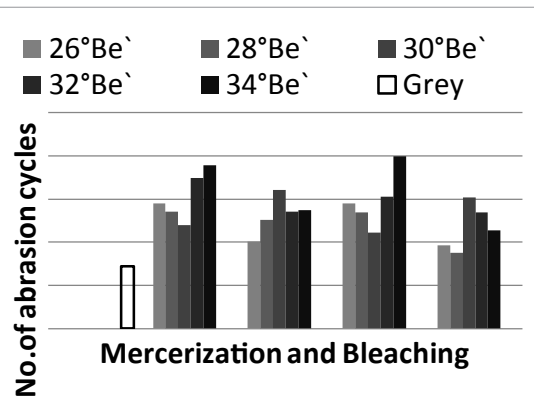

Figure 5: Effect of mercerization and bleachingan abrasion resistance at different conditions. 
Citation: El-Hadidy AM, El-Rys SM, El-Hossiny A (2015) The Influence of the Wet Processing Stages on Yarn Processability. J Textile Sci Eng 5: 214. doi:10.4172/2165-8064.1000214

abrasion resistance of mercerized yarns at temperatures $\left(19^{\circ} \mathrm{C}, 24^{\circ} \mathrm{C}\right)$ and at five different $\mathrm{NaOH}$ concentrations. It can be clearly seen that there was a greatly increase in the abrasion resistance of the yarns after both mercerization and bleaching compared to grey yarn. This increase in the abrasion resistance after $\mathrm{NaOH}$ treatment can be attributed to the degree of substitution of $\mathrm{O}-\mathrm{Na}$ groups in the cotton fiber. This finding was in agreement with that of Subramaniam [7]. The abrasion resistance increased after mercerization from ( 48 to 76 ) no. of abrasion cycles with average value (61) at temperature $19^{\circ} \mathrm{C}$, and from (45 to 80 ) no. of abrasion cycles with average value (60) at temperature $24^{\circ} \mathrm{C}$.

After bleaching, abrasion resistance decreased compared to mercerized yarns. This is in fact normally because there is a relation between the strength and abrasion of yarn. As shown, abrasion resistance of bleached yarn increased from (41 to 64) cycles of abrasion with average value (53) cycles of abrasion at temperature $19^{\circ} \mathrm{C}$, and from (35 to 61) cycles of abrasion with average value (47) at temperature $24^{\circ} \mathrm{C}$.

Abrasion of the yarn is followed by the gradual removal of fibers from the yarns when they are subjected to repeated distortion. Factors affecting the cohesion of the fibers in the yarn and yarn to yarn friction will have influence on the abrasion resistance.

Figure 6 shows the effect of two types of dyeing on the abrasion resistance of this yarn. After vat dyeing the abrasion resistance raised from (89 to 155) cycles of abrasion with average value (106) at temperature $19^{\circ} \mathrm{C}$, and from (31 to 97) cycles of abrasion with average value (56) at temperature $24^{\circ} \mathrm{C}$.

On the other hand, after reactive dyeing, the abrasion resistance

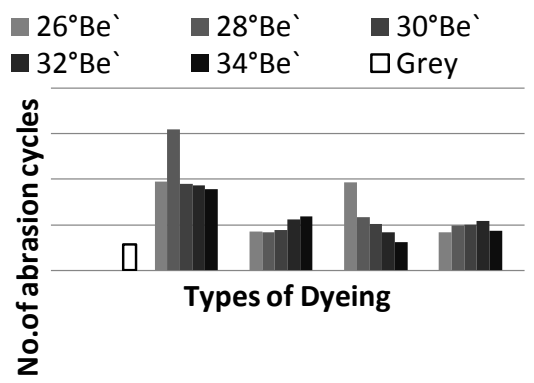

Figure 6: Effect of types of dyeing on abrasion resistance at different conditions.

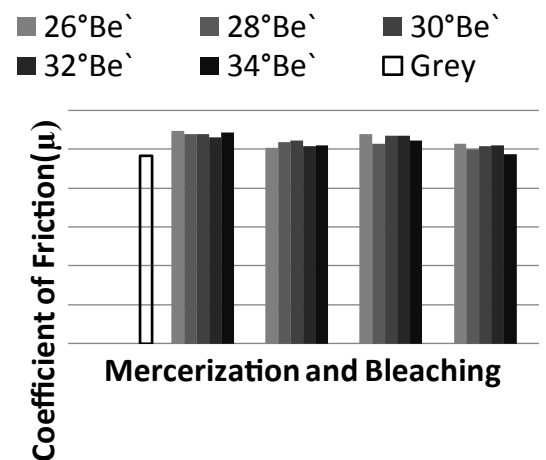

Figure 7: Effect of mercerization and bleaching on coefficient of friction at different conditions.

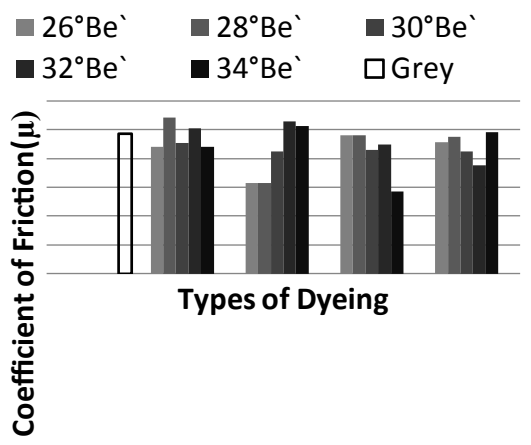

Figure 8: Effect of types of dyeing on coefficient of friction at different conditions.
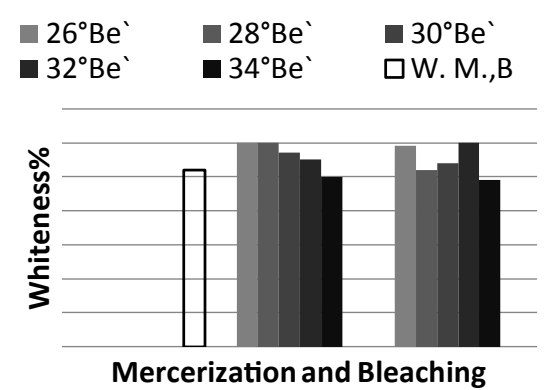

Figure 9: Effect of mercerization and bleaching on the degree of whiteness at different conditions.

increased from (42 to 59) cycles of abrasion with average value (49) at temperature $19^{\circ} \mathrm{C}$, and from (42 to54) cycles of abrasion with average value (48) at temperature $24^{\circ} \mathrm{C}$.

\section{Coefficient of friction}

Figure 7 shows the effect of mercerization and bleaching on the coefficient of friction of mercerized yarns at temperatures $\left(19^{\circ} \mathrm{C}\right.$, $24^{\circ} \mathrm{C}$ ) and at five different $\mathrm{NaOH}$ concentrations. The results showed that coefficient of friction increased after mercerization and bleaching compared to grey yarn. After mercerization, it ranged between 0.266 and 0.274 at temperature $19^{\circ} \mathrm{C}$, and between 0.258 and 0.27 at temperature $24^{\circ} \mathrm{C}$. Similarly to abrasion resistance, the coefficient of friction of yarns after bleaching decreased compared to mercerization, where, the coefficient of friction of yarns after bleached ranged between 0.252 and 0.262 at temperature $19^{\circ} \mathrm{C}$, and between 0.244 and 0.258 at temperature $24^{\circ} \mathrm{C}$. These findings were in agreement with those of Subramaniam [7].

Figure 8 illustrates the effect of two types of dyeing on the coefficient of friction of this yarn. After vat dyeing, it ranged between 0.22 and 0.27 at temperature $19^{\circ} \mathrm{C}$, and between 0.142 and 0.24 at temperature $24^{\circ} \mathrm{C}$. Besides, after reactive dyeing, coefficient of friction ranged between 0.158 and 0.264 at temperature $19^{\circ} \mathrm{C}$, and between 0.188 and 0.246 at temperature $24^{\circ} \mathrm{C}$.

\section{Degree of whiteness}

Figure 9 shows the effect of mercerization and bleaching on the degree of whiteness of mercerized yarns at temperatures $\left(19^{\circ} \mathrm{C}, 24^{\circ} \mathrm{C}\right)$ and at five different $\mathrm{NaOH}$ concentrations. The degree of whiteness was measured compared to the standard degree of whiteness of 
Citation: El-Hadidy AM, El-Rys SM, El-Hossiny A (2015) The Influence of the Wet Processing Stages on Yarn Processability. J Textile Sci Eng 5: 214. doi:10.4172/2165-8064.1000214

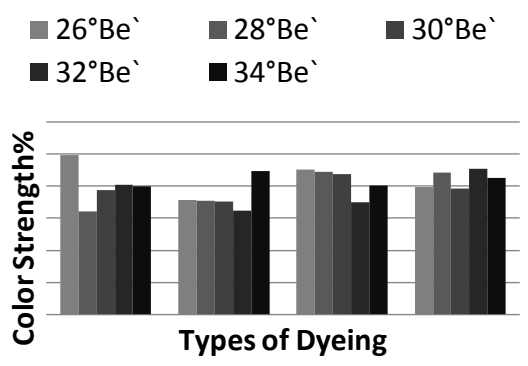

Figure 10: Effect of types of dyeing after mercerization on color strength at different conditions.

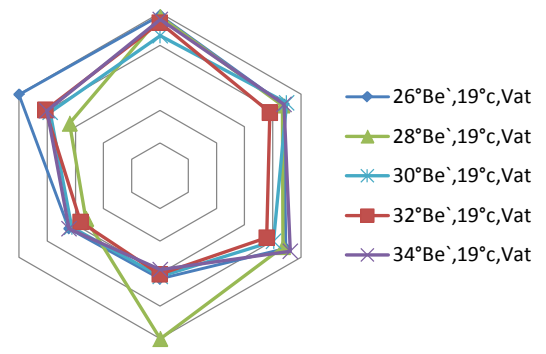

Figure 11: Overall evaluation of yarn properties at $19^{\circ} \mathrm{C}$, vat dyeing.

spectrophotometer tester which equals to (189). As shown the degree of whiteness improved after mercerization and bleaching more than after bleaching without mercerization. This improvement occurred due to the effect of mercerizing process which removes some color materials from cellulosic fibers.

After mercerization and bleaching, the degree of whiteness increased from $(50 \%$ to $60 \%)$ at temperature $19^{\circ} \mathrm{C}$, and from $(49 \%$ to $60 \%$ ) at temperature $24^{\circ} \mathrm{C}$.

\section{Color strength}

Figure 10 shows the effect of types of dyeing after mercerization on the color strength of mercerized yarns at temperatures $\left(19^{\circ} \mathrm{C}\right.$, $24^{\circ} \mathrm{C}$ ) and at five different $\mathrm{NaOH}$ concentrations. Color strength was measured compared to two dyed samples with vat and reactive dyes but without mercerization. In general, there was an increase in color strength in reactive dyeing more than vat dyeing. It can be clearly seen that after vat dyeing, color strength increased from (160\% to $248 \%)$ with average value $(201 \%)$ at temperature $19^{\circ} \mathrm{C}$, and from $(161 \%$ to $223 \%)$ with average value $(183 \%)$ at temperature $24^{\circ} \mathrm{C}$.

This increase may be because mercerizing process converts fibers to cylindrical shape leading to increase the spaces between the fibers, so the dye molecules can easily penetrate to the fibers and increase the color strength of this vat dye. Also, results showed an increase in color strength of reactive dyeing from (174\% to $226 \%)$ with average value $(208 \%)$ at temperature $19^{\circ} \mathrm{C}$, and from $(195 \%$ to $227 \%)$ with average value $(210 \%)$ at temperature $24^{\circ} \mathrm{C}$ because molecules of this reactive dye are bonded with covalent bonds with the fibers.

\section{Overall Evaluation of Yarn Properties}

In order to evaluate the overall effect of chemical treatments on the final properties of the yarns, the radar chart statistical method was used. For each level of each of the three parameters of the treatment, the processability index i.e. The ratio of the yarn polygon area before and after treatment was determined.

Figure 11 represents the processability chart for each level of $\mathrm{NaOH}$ concentrations at temperature $19^{\circ} \mathrm{C}$ and vat dyeing. It was found that the highest area of radar chart was occurred at $26^{\circ} \mathrm{Be}$ ' as shown in Table 3 while the lowest area was occurred at $32^{\circ} \mathrm{Be}$.

Figure 12 represents the process ability chart for each level of $\mathrm{NaOH}$ concentrations at temperature $19^{\circ} \mathrm{C}$ and reactive dyeing. It was found from the determined index that shown in Table 3 the highest area of radar chart was occurred at $26^{\circ} \mathrm{Be} e^{\prime}$ while the lowest area was occurred at $32^{\circ} \mathrm{Be}$.

Figure 13 represents the processability chart for each level of $\mathrm{NaOH}$ concentrations at temperature $24^{\circ} \mathrm{C}$ and vat dyeing. It was found from the determined index that shown in Table 3 the highest area of radar chart was occurred at $34^{\circ} \mathrm{Be}$ ' while the lowest area was occurred at $32^{\circ} \mathrm{Be}^{\prime}$.

Figure 14 represents the process ability chart for each level of $\mathrm{NaOH}$ concentrations at temperature $24^{\circ} \mathrm{C}$ and reactive dyeing. It was found from the determined index that shown in Table 3 the highest area of radar chart was occurred at $28^{\circ} \mathrm{Be}^{\prime}$ while the lowest area was occurred at $30^{\circ} \mathrm{Be}$. It was noticed that the vat dyeing maintain the physical properties generally more than reactive dyeing. As, the average of improvement in properties of yarns in case of vat dyeing was more

\begin{tabular}{|l|l|l|l|l|l|l|}
\hline $\begin{array}{l}\text { Temperature } \\
\left({ }^{\circ} \mathbf{C}\right)\end{array}$ & $\begin{array}{l}\text { Types of } \\
\text { Dyeing }\end{array}$ & $\mathbf{2 6}$ & $\mathbf{2 8}$ & $\mathbf{3 0}$ & $\mathbf{3 2}$ & $\mathbf{3 4}$ \\
\hline $\mathbf{1 9}$ & Vat & $70.90813^{*}$ & 66.06878 & 59.0121 & 55.78814 & 64.17274 \\
\hline \multirow{2}{*}{$\mathbf{2 4}$} & Reactive & 60.63058 & 55.17666 & 54.49425 & 37.75236 & 57.82358 \\
\hline & Vat & 60.00243 & 46.98462 & 53.61165 & 46.34582 & 68.10022 \\
\cline { 2 - 7 } & Reactive & 52.55869 & 64.52037 & 46.16233 & 52.45861 & 48.04597 \\
\hline
\end{tabular}

*Actual area/ideal area.

Table 3: Total area of overall yarn properties.

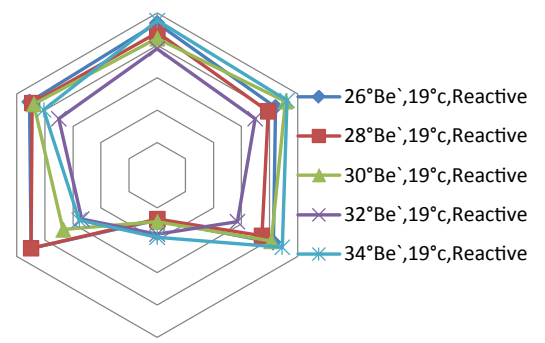

Figure 12: Overall evaluation of yarn properties at $19^{\circ} \mathrm{C}$, reactive dyeing.

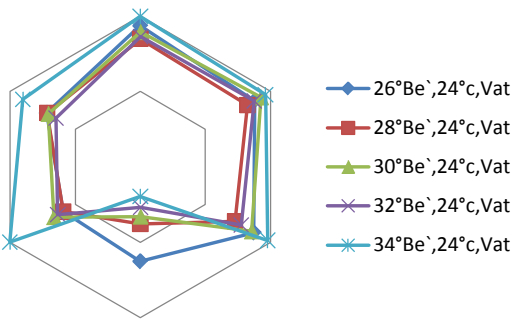

Figure 13: Overall evaluation of yarn properties at $24^{\circ} \mathrm{C}$,vat dyeing. 


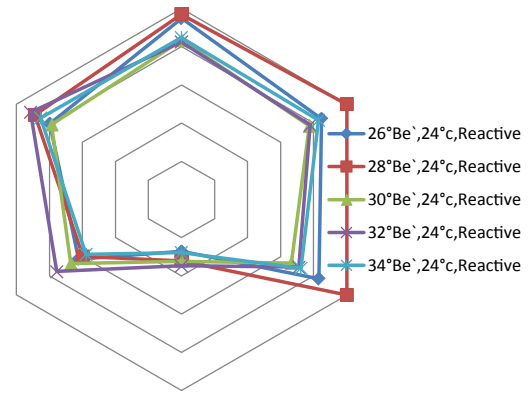

Figure 14: Overall evaluation of yarn properties at $24^{\circ} \mathrm{C}$, reactive dyeing.

than that of reactive dyeing in both cases $19^{\circ} \mathrm{C}$ and $24^{\circ} \mathrm{C}$ (Table 3 ).

\section{Conclusion}

Mercerizing process of yarns at different $\mathrm{NaOH}$ concentrations, and at different temperatures, followed by bleaching and dyeing with vat and reactive dyeing have an influence on the final properties of yarns.

After mercerization, there was an increase in the breaking -load in case of $24^{\circ} \mathrm{C}$ more than $19^{\circ} \mathrm{C}$ compared to unmercerized (grey) yarn.

- The results showed that the increasing in the breaking -load after vat dyeing was higher than reactive dyeing in both cases $19^{\circ} \mathrm{C}$ and $24^{\circ} \mathrm{C}$ compared to grey yarn.

- There was an increase in the breaking force after mercerization more than after bleaching compared to grey yarn.

- The yarn count increased after both mercerization and bleaching compared to grey yarn.

- There was a greatly increase in the abrasion resistance of the yarns after both mercerization and bleaching compared to grey yarn.

- Also after dyeing the abrasion resistance increased compared to untreated yarn.

- The results showed that coefficient of friction increased after mercerization and bleaching compared to grey yarn.
- After dyeing, coefficient of friction had values close to/or less than grey yarn.

- In general, there is an increase of the color properties for both vat and reactive dyeing compared to unmercerized samples because of the mercerization effect.

- The degree of whiteness improved after mercerization and bleaching more than after bleaching without mercerization.

- From the overall evaluation of physical properties by performance diagram, It was found that the highest area of radar chart was occurred at $26^{\circ} \mathrm{Be}$ at temperature $19^{\circ} \mathrm{C}$, vat dyeing and at temperature $19^{\circ} \mathrm{C}$, reactive dyeing.

- The highest area of radar chart was occurred at $34^{\circ} \mathrm{Be}$ ' at temperature $24^{\circ} \mathrm{C}$ and vat dyeing.

- The highest area of radar chart was occurred at $28^{\circ} \mathrm{Be} e^{\prime}$ at temperature $24^{\circ} \mathrm{C}$ and reactive dyeing.

- Vat dyeing maintain the physical properties of the fabric generally more than reactive dyeing.

\section{References}

1. Wakida T, Lee M, Park SJ, Hayashi A (2002b) Hot mercerization of cottons Fiber 58: 304-307.

2. Arthur D, Broadbent (2001) Basic Principles of Textile Coloration. Society of Dyers and Colourists.

3. Jordanov I, Mangovska B (2011) Accessibility of mercerized, bioscoured and dried cotton yarns. Indian Journal of Fiber Textile 36: 259-265

4. Mehdi A, Abdulreza Z, Eddin BSJ (2012) Optimization of Parameters Influencing Mercerization Using RSM Method in Order to Increase the Tensile Strength of Mercerized Yarn. Fibers and Textiles in Eastern Europe 20: 30-35.

5. Samei N, Mortazavi SM, Rashidi A, Najjar SS (2008) Changes in Physical Properties of Hot Mercerized Ring and Open-end Spun Cotton Yarns. Iranian Polymer Journal 17: 937-945.

6. Jordanov I, Mangovska B (2009) Characterization on Surface of Mercerized and Enzymatic Scoured Cotton after Different Temperature of Drying. The Open Textile Journal 2: 39-47.

7. Farid F, Roshanara, Subramaniam V (2014) Effect of Chemical Treatment on the Characteristics of Regular and Compact Cotton Spun Yarns. International Journal of Research in Engineering and Technology.

8. Ibrahim S, Militký J (2015) Knitting Ability Textile Faculty. Technical University of Liberce. 